https://helda.helsinki.fi

\title{
Authors' reply to Lee and colleagues
}

\section{Jarvinen, Teppo}

2015-07-14

Jarvinen , T , Michaelsson , K , Jokihaara , J , Collins , G S , Perry , T L , Mintzes , B , Musini , V , Erviti , J , Gorricho , J , Wright, J M \& Sievanen, H 2015 , ' Authors' reply to Lee and colleagues ' , BMJ : British Medical Journal , vol. 351 , 3737 . https://doi.org/10.1136/bmj.h3737

http://hdl.handle.net/10138/177553

https://doi.org/10.1136/bmj.h3737

publishedVersion

Downloaded from Helda, University of Helsinki institutional repository.

This is an electronic reprint of the original article.

This reprint may differ from the original in pagination and typographic detail.

Please cite the original version. 


\title{
Authors' reply to Lee and colleagues
}

\author{
Teppo Järvinen professor ${ }^{1}$, Karl Michaëlsson professor ${ }^{2}$, Jarkko Jokihaara registrar ${ }^{3}$, Gary S Collins \\ associate professor ${ }^{4}$, Thomas L Perry clinical assistant professor ${ }^{5}$, Barbara Mintzes senior lecturer ${ }^{6}$, \\ Vijaya Musini assistant professor ${ }^{5}$, Juan Erviti head ${ }^{7}$, Javier Gorricho senior evaluation officer ${ }^{8}$, \\ James M Wright professor ${ }^{5}$, Harri Sievänen research director ${ }^{9}$
}

${ }^{1}$ Department of Orthopaedics and Traumatology, University of Helsinki and Helsinki University Central Hospital, Helsinki, Finland; ${ }^{2}$ Department of Surgical Sciences, Section of Orthopaedics, Uppsala University, Uppsala, Sweden; ${ }^{3}$ Department of Hand Surgery, Tampere University Hospital, Tampere, Finland; ${ }^{4}$ Centre for Statistics in Medicine, Botnar Research Centre, University of Oxford, Oxford, UK; ${ }^{5}$ Departments of Anesthesiology, Pharmacology, and Therapeutics and Medicine, University of British Columbia, Vancouver, BC, Canada; ${ }^{6}$ Faculty of Pharmacy and Charles Perkins Centre, University of Sydney, Sydney, Australia; ${ }^{7}$ Drug Information Unit, Navarre Regional Health Service, Pamplona, Navarre, Spain; ${ }^{8}$ Department of Health, Government of Navarre, Pamplona, Navarre, Spain; ${ }^{9}$ UKK Institute for Health Promotion Research, Tampere, Finland

Lee and colleagues of the National Bone Health Alliance (NBHA) call for expanded fracture liaison services (FLS), because secondary prevention represents the most productive opportunity for pharmacotherapy. Intuitively this seems logical, but supporting arguments do not stand up to scrutiny. ${ }^{12}$

The effectiveness of FLS should be tested in randomised controlled trials (RCTs) to see whether this approach can achieve the "quality outcomes" referred to 1 - prevention of second fractures-as opposed to the proportion of patients evaluated or prescribed drugs. Presently, evidence on FLS is limited to observational studies or invalid modelling based cost effectiveness extrapolations. ${ }^{3}$

Lee and colleagues cite HORIZON—-the only secondary prevention trial of patients after a hip fracture-as proof that FLS are effective. ${ }^{4}$ However, after median follow-up of nearly two years, secondary hip fracture rates did not differ significantly with zoledronic acid versus placebo $(2.0 \%$ v $3.5 \%)$. There were fewer clinical non-vertebral fractures $(7.6 \% v 10.7 \%$; absolute risk reduction $3.1 \%$; relative risk reduction $27 \%$; $\mathrm{P}=0.03)$ and fewer clinical vertebral fractures $(1.7 \%$ v $3.8 \%$; $2.1 \% ; 55 \% ; \mathrm{P}=0.02)$. But even under "artificial" circumstances for assessing effectiveness, ${ }^{35}$ patients did not benefit from pharmacotherapy. Fundamental flaws including early termination, selective outcome reporting, and loss to follow-up undermine HORIZON's generalisability. Moreover, participants' mean age was only 74 years, whereas the mean age of patients with hip fracture is about 80 years in Europe, and more than three in four hip fractures occur in people over 75.

We share NBHA's desire to prevent clinically important fractures. Nonetheless, we must abstain from interventions (a) that are not proved effective, (b) for which the ratio of potential benefit to potential harm is poor, or (c) for which cost prohibits the development of more effective alternative strategies. Pending demonstration of the utility of FLS in a valid RCT, we recommend discretion in advocating and implementing this concept.

Vigorous discussion of current scientific evidence on how best to reduce fracture burden is important. Orthodoxy, inattention to methodological problems in RCTs, and lack of transparency concerning competing interests remain barriers to achieving the best and most cost effective care for our patients. ${ }^{6}$

Competing interests: We have read and understood BMJ policy on declaration of interests and declare BM has provided expert testimony in a Canadian class action lawsuit on postmenopausal hormone therapy and breast cancer risks. TLNJ is the Jane and Aatos Erkko foundation clinical professor of orthopaedics and traumatology at the University of Helsinki and is supported by unrestricted academic grants from the Academy of Finland and the Sigrid Juselius Foundation. Authors from the University of British Columbia are supported by an operating grant from the government of British Columbia to the UBC Therapeutics Initiative.

Full response at: www.bmj.com/content/350/bmj.h2088/rr-22.

1 Lee DB, Adler RA, Gagel RF. Treatment of osteoporosis is not futile. BMJ 2015;351:h3274 2 Järvinen TLN, Michaëlsson K, Jokihaara J, et al. Overdiagnosis of bone fragility in the quest to prevent hip fracture. BMJ 2015;350:h2088. (26 May.)

3 Jarvinen TL, Sievanen $\mathrm{H}$, Kannus $\mathrm{P}$, et al. The true cost of pharmacological disease prevention. BMJ 2011;342:d2175.

4 Lyles KW, Colon-Emeric CS, Magaziner JS, et al. Zoledronic acid and clinical fractures and mortality after hip fracture. N Engl J Med 2007;357:1799-809.

5 Djulbegovic B, Paul A. From efficacy to effectiveness in the face of uncertainty: indication creep and prevention creep. JAMA 2011;305:2005-6. 
6 Jarvinen TL, Jokihaara J, Guy P, et al. Conflicts at the heart of the FRAX tool. CMAJ 2014;186:165-7.
Cite this as: BMJ 2015;351:h3737

๑ BMJ Publishing Group Ltd 2015 